\title{
STUDI KELAYAKAN PERUMAHAN BERSUBSIDI PENUNJANG KAWASAN INDUSTRI (LOKASI : SAGA, BALARAJA, KABUPATEN TANGERANG)
}

\author{
Vania Putri Azaria ${ }^{1)}$, Priyendiswara Agustina Bela ${ }^{2)}$, Bambang Deliyanto ${ }^{3)}$
}

\footnotetext{
1)Program Studi S1 PWK, Fakultas Teknik, Universitas Tarumanagara, vaniaptzr20@gmail.com

2)Program Studi S1 PWK, Fakultas Teknik, Universitas Tarumanagara, hedy.agustina@gmail.com

3)Program Studi S1 PWK, Fakultas Teknik, Universitas Tarumanagara, deli.bambang@gmail.com
}

Masuk: 10-08-2020, revisi: 07-09-2020, diterima untuk diterbitkan: 25-09-2020

Abstrak

Rumah menjadi salah satu kebutuhan primer bagi masyarakat, selain sebagai tempat tinggal rumah juga merupakan tempat berlindung dan sebagai tempat berkumpul sekaligus sebagai barang investasi. Bagi masyarakat berpenghasilan rendah kesenjangan antara kebutuhan penyediaan rumah dari tahun ke tahun masih terus terjadi, hal itu dikarenakan masih rendahnya daya beli atau terbatasnya akses ke sistem pembiayaan rumah. Oleh karena itu pemerintah melalui perbankan merealisasikan pemeberian kredit yang disebut dengan KPR (Kredit Pemilikan Rumah). Di Indonesia dikenal dengan 2 jenis KPR yaitu KPR subsidi dan KPR non subsidi. KPR subsidi umumnya ditujukan untuk Masyarakat Berpenghasilan Rendah (MBR). KPR jenis ini disediakan oleh bank sebagai bagian dari program pemerintah bekerjasama dengan Kementerian Pekerjaan Umum dan Perumahan Rakyat (PUPR) untuk membantu mendanai kepemilikan rumah masyarakat yang akan diberikan subsidi berupa keringanan kredit atau uang muka. Sedangkan KPR non subsidi diperuntukkan bagi masyarakat umum yang memenuhi persyaratan yang ditetapkan oleh bank penyedia KPR. PT. Prima Graha Nusa Sempana saat ini sedang merencanakan pembangunan perumahan bersubsidi dengan target pasar buruh pabrik, hal itu karena lahan tersebut berada di Kecamatan Balaraja tepatnya di Kelurahan Saga, dimana Balaraja merupakan salah satu pusat industri yang terdapat di Kabupaten Tangerang. Sebelum melakukan pengembangan pada lahan seluas $13.5 \mathrm{Ha}$, akan dilakukan terbelih dahulu studi kelayakan terhadap lahan tersebut. Studi kelayakan dilakukan untuk mengetahui layak atau tidaknya pengembangan tersebut dan untuk mengetahui keuntungan dan kerugian pada pengembangan tersebut. Selain itu studi kelayakan dilakukan agar pengembang mendapatkan hasil yang maksimal tergadap pengembangan tersebut.

\section{Kata kunci: perumahan subsidi; properti; studi kelayakan}

\begin{abstract}
House is one of the primary needs in society. Not only a living place, but a house is also a protection, gathering place, and investment. For low-income families, the gap between supply and demand for houses occur every year. It happens because of the low buying power or limited access to the house financing system. Therefore, through the banking industry, the government realizes the housing loan facility called the mortgage. There are 2 types of mortgages in Indonesia, i.e., subsidized mortgage and non-subsidized mortgage. The subsidized mortgage mainly targets Low-Income Families (LIF). The bank provides this type as the government program cooperating with the Ministry of Public Works and Public Housing to help finance subsidized houses in the form of loan or down payment facility. Meanwhile, the non-subsidized mortgage targets general society that fulfilled the mortgage requirements from the providing bank. PT Prima Graha Nusa Sempana currently plans to develop subsidized housing estate that targets factory workers. The land is located in Balaraja Sub-district, precisely at Saga Village, one of the industrial centers in Tangerang Regency. Before developing a $13.5 \mathrm{Ha}$ land, an eligibility study is required. The study is conducted to discover the development eligibility and to count the profit and loss from the development. Besides that, an eligibility study is conducted to achieve a maximum result from the development.
\end{abstract}

Keywords: feasibility study, property; subsidized housing 


\section{PENDAHULUAN}

Perkembangan ekonomi masyarakat dan pertambahan penduduk yang semakin pesat mempengaruhi sektor pembangunan di suatu daerah. Salah satu kebutuhan primer bagi masyarakat yang tidak dapat dihindari yaitu rumah tinggal. Rumah merupakan salah satu kebutuhan manusia yang mendasar selain sebagai tempat tinggal rumah juga merupakan tempat berlindung dan sebagai tempat berkumpul serta berlangsungnya kegiatan keluarga, sekaligus sebagai barang investasi. Menurut Mangeswuri (2016:1) dari tahun ke tahun kesenjangan antara kebutuhan penyediaan rumah masih terjadi khususnya bagi masyarakat berpenghasilan rendah, disebabkan karena masih rendahnya daya beli atau terbatasnya akses ke sistem pembiayaan perumahan.

Oleh karena itu, pemerintah melalui perbankan merealisasikan pemberian kredit. Kredit Perumahan Rakyat (KPR) merupakan salah satu produk yang berkembang di Indonesia. Produk Kredit Perumahan Rakyat (KPR) juga dimiliki hampir seluruh perbankan di Indonesia sehingga bank bersaing memberikan bunga ringan dan jangka waktu yang relatif lebih lama untuk menarik minat nasabah. Di Indonesia, dikenal 2 (dua) jenis KPR. Berdasarkan persyaratan penerima pinjaman dikenal KPR subsidi dan KPR non subsidi. KPR subsidi umumnya ditujukan untuk Masyarakat Berpenghasilan Rendah (MBR). Sedangkan KPR non subsidi adalah KPR yang diperuntukkan bagi masyarakat umum yang memenuhi persyaratan yang ditetapkan oleh bank penyedia KPR.

PT. Prima Graha Nusa Sempana saat ini sedang merencanakan pembangunan perumahan bersubsidi dengan target pasar buruh pabrik. Lahan pengembangan milik PT. Prima Graha Nusa Sempana adalah seluas 13,5 Hektar berlokasi di Jalan Raya Saga - Bunar, Kecamatan Balaraja, Kabupaten Tangerang. Sehingga penulis dalam rangka melakukan tugas akhir, penulis ingin melakukan studi kelayakan pengembangan lahan milik PT. Prima Graha Nusa Sempana sebagai area perumahan tapak bersubsidi.

Rumusan masalah dalam penelitian ini ialah, dalam melakukan pengembangan perumahan subsidi, keuntungan yang didapat pihak pengembang biasanya tidak menentu bisa untung dan bisa tidak hal itu dikarenakan harga rumah subsidi sudah ditentukan oleh pemerintah. Selain itu masyarakat disekitar tapak sebagian besar memiliki tingkat perekonomian menengah kebawah. Maka untuk menjawab rumusan masalah diatas, penulis melakukan penelitian ini dengan tujuan mengetahui kompetitor disekitar tapak selain itu juga untuk menentukan alternatif jumlah unit yang akan dibangun dan alternatif bahan bangunan yang akan digunakan agar proyek pembangunan Perumahan Saga Residence mendapatkan hasil yang maksimal.

\section{KAJIAN LITELATUR}

\section{Studi Kelayakan}

Studi kelayakan adalah penelitian dan analisis terhadap suatu rencana usaha yang menyangkut berbagai aspek, termasuk aspek pemasaran, operasi, SDM, lingkungan, pasar, dan keuangan, sehingga diketahui rencana usaha tersebut layak atau tidak layak bila dilaksanakan (R.W. Suparyanto, 2016). Definisi lain dari studi kelayakan menurut (Husnan, 2000), studi kelayakan proyek merupakan penelitian mengenai bisa atau tidaknya suatu proyek investasi dilaksanakan dengan berhasil. Pada umumnya studi kelayakan mencakup 3 aspek, yaitu:

a. Manfaat ekonomis proyek tersebut bagi proyek itu sendiri (sering juga disebut manfaat financial) yang berarti apakah proyek itu cukup menguntungkan atau tidak menguntungkan apabila dibandingkan dengan resiko proyek tersebut.

b. Manfaat proyek tersebut bagi negara tempat proyek itu dilaksanakan. Yang menunjukkan manfaat proyek tersebut terhadap ekonomi makro suatu negara. 
c. Manfaat sosial proyek tersebut bagi masyarakat sekitar proyek tersebut. Banyak manfaat yang dapat diperoleh dari kegiatan investasi. Diantaranya yaitu penyerapan tenaga kerja, peningkatan output yang dihasilkan, penghematan devisa ataupun penambahan devisa dan lain-lain.

\section{Properti}

Menurut (Kotler, 2005) properti adalah hak kepemilikan tak berwujud baik itu berupa benda nyata (real estate) maupun financial (saham dan obligasi). Sedangkan menurut Robert \& Floyd $(1991$, p4) properti adalah semua bangunan yang ada diatas permukaan bumi yang menjulang ke angkasa yang melekat secara permanen baik secara alamiah maupun dengan campur tangan manusia. Berdasarkan fungsi dan tujuan penggunaannya (Santoso, 2009), properti dapat diklasifikasikan menjadi 4 (empat) golongan atau kategori, yaitu komersial, hunian, industri, dan fasilitas umum.

\section{Kredit Kepemilikan Rumah (KPR)}

Kredit Pemilikan Rumah (KPR) merupakan suatu fasilitas kredit yang disediakan oleh perbankan kepada para nasabah perorangan yang akan membeli rumah. Sistem yang dilakukan dari KPR itu sendiri ialah dengan jaminan/ agunan berupa rumah dengan skema pembiayaan hingga $90 \%$ dari harga rumah dan yang dijadikan jaminan/ agunan ialah rumah yang akan dibeli itu sendiri untuk KPR pembelian. Prinsip KPR adalah membiayai terlebih dahulu biaya pembelian rumah atau pembangunan rumah, dan untuk membayar balik dana yang sudah diberikan dilakukan dengan cicilan. Saat ini di Indonesia dikenal ada 2 jenis KPR yaitu KPR subsidi dan KPR nonsubsidi. KPR subsidi umumnya ditujukan untuk Masyarakat Berpenghasilan Rendah (MBR). Sedangkan KPR non subsidi adalah KPR yang diperuntukkan bagi masyarakat umum yang memenuhi persyaratan yang ditetapkan oleh bank penyedia KPR.

\section{Program Subsidi Rumah}

Program pemerintah mengenai subsidi rumah memiliki beberapa bentuk bantuan yang akan diberikan kepada masyarakat. Beberapa bentuk bantuannya antara lain :

a. Fasilitas Likuiditas Pembiayaan Perumahan (FLPP) : merupakan suatu dukungan fasilitas likuiditas pembiayaan perumahan kepada MBR yang pengelolaannya dilaksanakan oleh Kementerian PUPR.

b. Subsidi Bantuan Uang Muka (SBUM) : merupakan Subsidi pemerintah yang diberikan kepada MBR (masyarakat berpenghasilan rendah) dalam rangka pemenuhan sebagian/ seluruh uang muka perolehan rumah.

c. KPR SSB : merupakan Kredit kepemilikan rumah yang diterbitkan oleh Bank Pelaksana secara konvensional yang mendapat pengurangan suku bunga melalui Subsidi Bunga Kredit Perumahan.

d. Kredit Pemilikan Rumah Subsidi Selisih Marjin (KPR SSM) : adalah pembiayaan pemilikan rumah yang diterbitkan oleh Bank Pelaksana dengan prinsip syariah yang mendapat pengurangan marjin melalui Subsidi Bunga Kredit Perumahan.

e. Subsidi Bunga Kredit Perumahan : adalah Subsidi Pemerintah yang diberikan kepada masyarakat berpenghasilan rendah berupa selisih suku bunga/marjin antara kredit/pembiayaan pemilikan rumah yang menggunakan suku bunga komersial dengan suku bunga/marjin kredit/pembiayaan pemilikan rumah yang dibayar oleh debitur/nasabah ditetapkan oleh Pemerintah.

\section{Industri}

Industri adalah suatu kegiatan produksi dan manufaktur yang melibatkan berbagai kegiatan sehingga terjadi proses untuk menghasilkan suatu produk. Baik jenis maupun penggolongannya juga berbeda-beda berdasarkan jenis produk yang akan diproduksi dan cara pembuatannya. Hal 
ini bisa didasarkan pada tempat bahan baku hingga besaran modal yang dimiliki. Sebagai kegiatan ekonomi yang mengolah bahan baku menjadi bahan jadi, dalam prosesnya dibutuhkan pemanfaatan sumber daya industri. Karena itulah akan dihasilkan barang yang memiliki nilai tambah atau manfaat yang lebih tinggi.

\section{Developer}

Dalam Undang-Undang Perlindungan Konsumen developer masuk dalam kategori sebagai pelaku usaha. Pengertian Pelaku Usaha dalam Pasal 1 angka 3 Undang-Undang Nomor 8 tahun 1999 tentang Perlindungan Konsumen yaitu: "Pelaku Usaha adalah setiap orang perseorangan atau badan usaha, baik yang berkedudukan atau melakukan kegiatan dalam wilayah hukum Negara Republik Indonesia, baik sendiri maupun bersama-sama melalui perjanjian menyelenggarakan kegiatan usaha dalam berbagai bidang ekonomi" (Winarto,2008).

\section{METODE}

Objek studi dalam penelitian ini adalah lahan kosong seluas 13.5 Ha milik PT Prima Graha Nusa Sempana yang berlokasi di Saga, Balaraja, Kabupaten Tangerang, Banten. Data yang didapatkan untuk penelitian ini dikumpulkan dari berbagai sumber, yaitu survei lapangan untuk mengetahui lokasi dan kondisi eksisting dari objek studi, saat survei lapangan penulis melakukan dokumentasi untuk menunjang data-data yang diperlukan berupa visualisasinya, wawancara dengan pihak pengembang untuk mengetahui data atau infornasi yang sifatnya tidak umum, serta data atau informasi dari media cetak dan media elektronik untuk mendapatkan data yang diperoleh secara tidak langsung. Metode deskriptif digunakan untuk menjelaskan keadaan lahan objek studi, metode kuantitatif digunakan untuk menghitung cashflow terhadap lahan yang akan dikembangkan. Untuk mendapatkan jumlah rumah dan harga rumah yaitu dengan cara melihat kondisi pasar disekitar tapak.

\section{DISKUSI DAN HASIL}

\section{Profil Objek Studi}

Lokasi objek studi berada di Kelurahan Saga, Kecamatan Balaraja, Kabupaten Tangerang. Lahan objek studi memiliki luas sebesar $135.000 \mathrm{~m} 2$ atau $13.5 \mathrm{Ha}$ dan berupa lahan kosong. Lahan objek studi ini milik PT Prima Graha Nusa Sempana dengan status lahan sebagian besar hak milik dan sisanya belum terdaftar. Dengan batas lahan sebagai berikut :

- Utara : Lahan Kosong

- Timur : Lahan Kosong

- Selatan : Lahan Kosong (Jalan $\mathrm{x}$ )

- Barat : Perumahan Salaka Nagara \& Lahan Kosong

Dan berikut ini merupakan batas lahan yang penulis dapat dari pihal developer yaitu PT Prima Graha Nusa Sempana. 


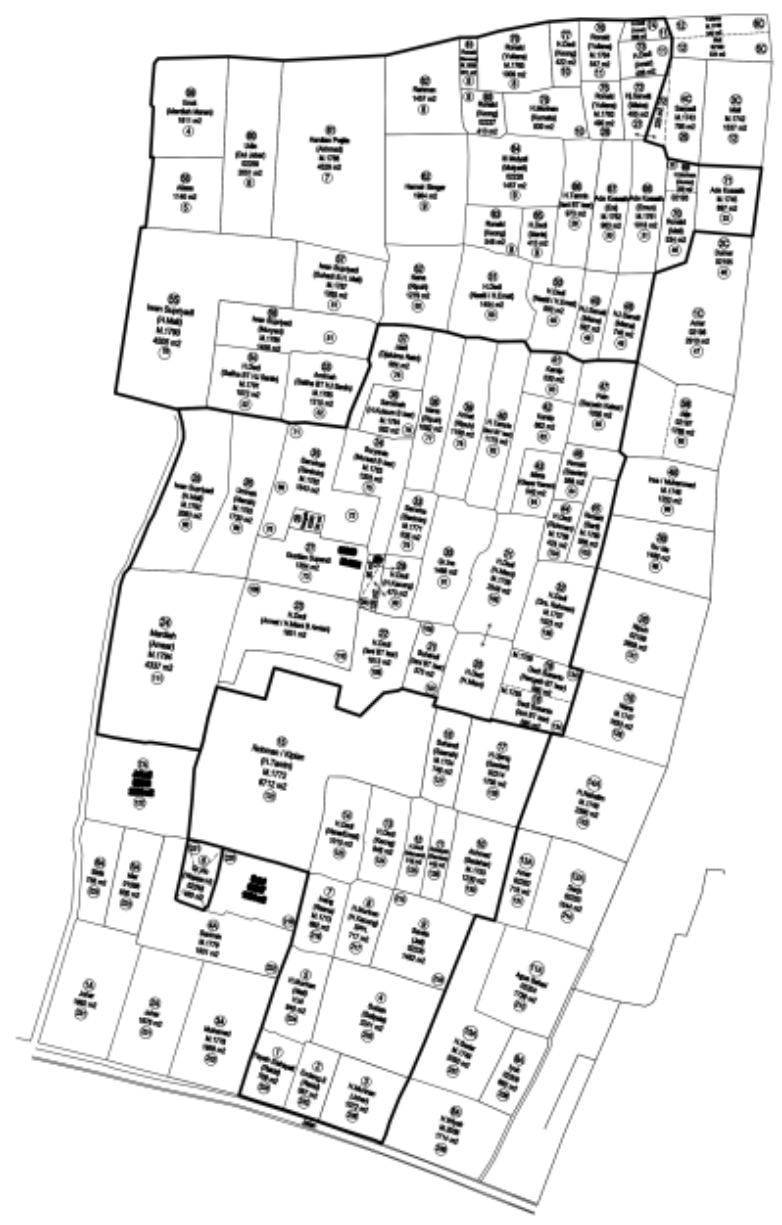

Gambar 1. Batas Lahan Resmi Objek Studi Sumber: PT. Prima Graha Nusa Sempana, 2020

Lokasi objek studi berada di Kelurahan Saga, Kecamatan Balaraja, Kabupaten Tangerang. Lokasi makro objek studi menurut hak kepemilikan di dominasi oleh Hak Milik, sebagian Hak Guna Bangunan dan sisanya belum terdaftar. Mengenai nilai lahan data dari BPN menunjukkan bahwa nilai lahan objek studi adalah Rp 200.000,- hingga Rp 300.000,- lebih tepatnya ialah Rp 213.000,-Dapat dikatakan bahwa aksesibilitas menuju lokasi objek studi sangat dikit aksesnya, hanya melalui satu jalan kolektor yaitu Jalan Kresek, dan jarak dari Jalan Kresek menuju lokasi tapak masih cukup jauh. Untuk menuju tapak hanya dapat di akses menggunakan kendaraan pribadi. Akses utama menuju lokasi tapak adalah Jalan $X$ (belum memiliki nama jalan). Berikut ini merupakan beberapa alternatif jalan yang dapat dilalui untuk menuju lokasi objek studi, yaitu sebagai berikut:

Tabel 1. Aksesibilitas Menuju Tapak

\begin{tabular}{cccc}
\hline Asal & Rute & Akses Utama & Kelas Jalan \\
\hline $\begin{array}{c}\text { Kota Tangerang/ } \\
\text { Jakarta Barat }\end{array}$ & $\begin{array}{c}\text { Tol Jakarta-Merak - Exit Tol } \\
\text { Balaraja - Jl. Raya Kresek - Jl. Raya } \\
\text { Saga Bunar }\end{array}$ & Jl. Raya Saga Bunar & Tol \\
\hline Serang & $\begin{array}{c}\text { Jl. Pantura/ Jl. Tol Merak-Jakarta - } \\
\text { Exit Tol Balaraja Barat - Jl Kresek - } \\
\text { Jl. Raya Saga Bunar }\end{array}$ & Jl. Raya Saga Bunar & Tol / Arteri \\
\hline $\begin{array}{c}\text { Kab. Tangerang } \\
\text { (Utara) }\end{array}$ & $\begin{array}{l}\text { Jl. Raya Cadas Kukun - Jl. Raya } \\
\text { Merak - Jl. Kresek - Jl. Raya Saga } \\
\text { Bunar }\end{array}$ & Jl. Raya Saga Bunar & Lokal \\
\hline
\end{tabular}

Sumber: Hasil Olahan Penulis, 2020 


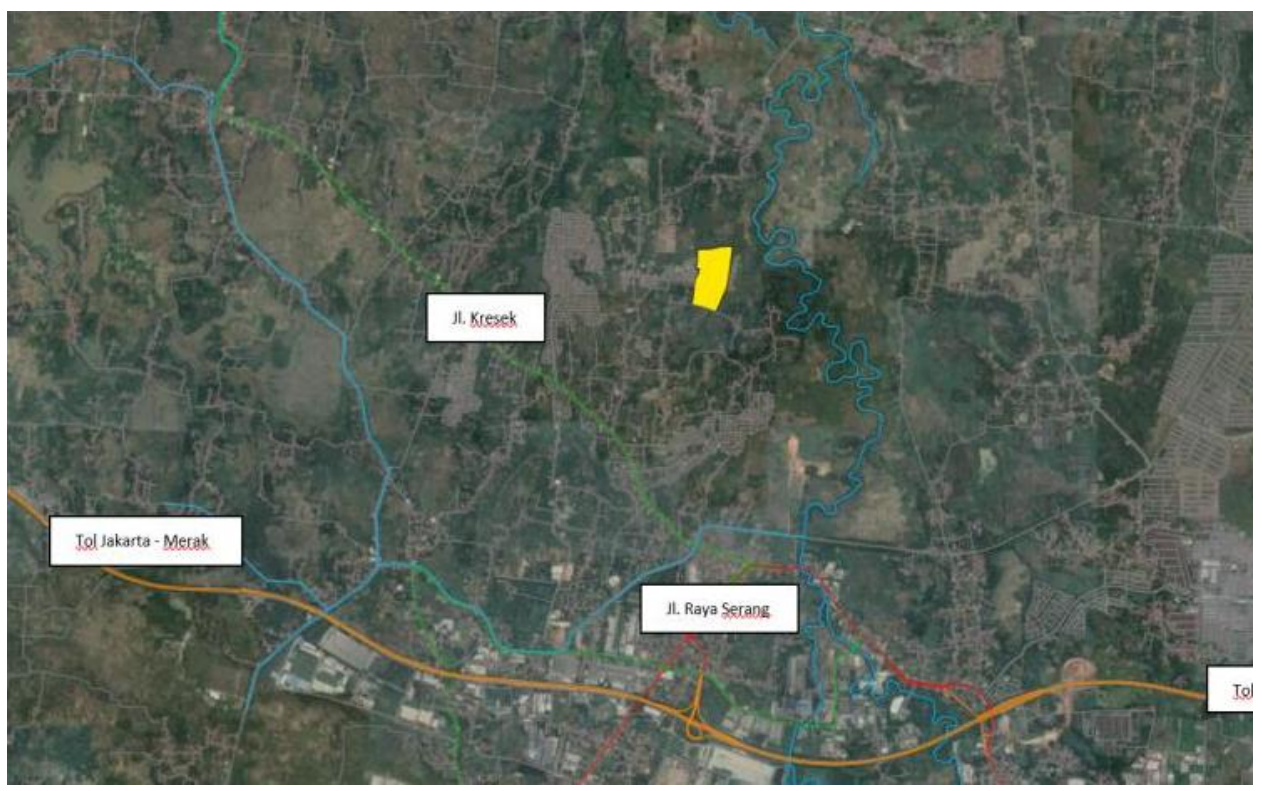

Gambar 2. Peta Jaringan Jalan

Sumber: Hasil Olahan Penulis, 2020

\section{Data Landed House}

Disekitar tapak didominasi oleh perumahan dan lahan kosong. Berikut ini merupakan data persebaran perumahan disekitar tapak.

Tabel 2. Persebaran Perumahan Disekitar Tapak

\begin{tabular}{|c|c|c|c|}
\hline No. & Nama Perumahan & Lokasi & $\begin{array}{l}\text { Tahun } \\
\text { Pengembangan }\end{array}$ \\
\hline 1. & Permata Balaraja & Saga, Kec. Balaraja, Tangerang & 1996 \\
\hline 2. & Griya Sutera Balaraja & $\begin{array}{l}\text { Jl. Raya Kresek, Tegal Kalibaru, Talagasari, } \\
\text { Kec. Balaraja, Tangerang }\end{array}$ & 2019 \\
\hline 3. & Duta Asri Balaraja & Saga, Kec. Balaraja, Tangerang & 2010 \\
\hline 4. & Saga Asri Balaraja & Saga, Kec. Balaraja, Tangerang & 2014 \\
\hline 5. & Bumi Mentari & Pekong, Saga, Kec. Balaraja & 2016 \\
\hline 6. & Graha Hijau Balaraja & Saga, Kec. Balaraja, Tangerang & 2018 \\
\hline 7. & Taman Balaraja & $\begin{array}{l}\text { Taman Balaraja, Parahu, Kec. Sukamulya, } \\
\text { Tangerang }\end{array}$ & 2002 \\
\hline 8. & Villa Ilhami Balaraja & Parahu, Kec. Sukamulya, Tangerang & 2017 \\
\hline 9. & Salaka Nagara & Saga, Kec. Balaraja, Tangerang & 2016 \\
\hline 10. & Bumi Asri Balaraja & Saga, Kec. Balaraja, Tangerang & \\
\hline 11. & $\begin{array}{l}\text { Pesona Saga } \\
\text { Residence }\end{array}$ & Saga, Balaraja, Tangerang & 2018 \\
\hline 12. & Villa Balaraja & Saga, Balaraja, Tangerang & 1995 \\
\hline 13. & $\begin{array}{l}\text { Graha Berlian } \\
\text { Balaraja }\end{array}$ & Merak, Sukamulya, Tangerang & 2016 \\
\hline 14. & Suvarna Sutera & $\begin{array}{l}\text { Jl. Padi Utama, Suka Harja, Kec. Sindang Jaya, } \\
\text { Tangerang }\end{array}$ & 2013 \\
\hline 15. & Telaga Bestari & Wana Kerta, Sindang Jaya, Tangerang & 1995 \\
\hline 16. & $\begin{array}{l}\text { Perumahan Eshal } \\
\text { Garden }\end{array}$ & & 2018 \\
\hline
\end{tabular}

Sumber: Hasil Olahan Penulis, 2020 


\section{Persebaran Fasilitas}

Dalam radius $5 \mathrm{Km}$ terdapat beberapa fasilitas, diantaranya fasilitas pendidikan, peribadatan, dan kesehatan. Untuk fasilitas peribadatan yang terdapat disekitar objek studi hanya Masjid, Musholla, dan Gereja. Untuk Fasilitar peribadatan disekitar objek studi terdapat SD, SMP, dan SMA tetapi tidak terdapat perguruan tinggi. Untuk fasilitas kesehatan dalam radius $5 \mathrm{Km}$ dari objek studi terdapat RSUD Balaraja dan rumah sakit swasta.

\section{Analisis Lokasi \& Tapak}

Aksesibilitas menjadi faktor yang paling penting dalam pengembangan properti. Fungsi aksesibilitas sendiri ialah untuk menunjukkan apakah lokasi tersebut memiliki lokasi yang strategis atau tidak. Tapak yang menjadi objek studi belum memiliki akses yang baik, hal itu dikarenakan masih sulitnya akses untuk mencapai tapak tersebut. Jika dari Jakarta dan Serang untuk menuju tapak melalui Jl. Tol Jakarta-Merak dan keluar di pintu Tol Balaraja Barat, setelah itu menuju Jl. Raya Kresek. Untuk mencapai tapak hanya memiliki satu akses yaitu melalui Jl. Raya Kresek lalu menuju Jl. Raya Saga Bunar, dan masih harus melalui Jl. Y untuk menuju tapak. Akses utama (JL. X) tapak hanya memiliki ROW 3 meter hanya muat dilalui oleh 1 mobil.

Dalam radius $5 \mathrm{Km}$ dari lokasi lahan tapak hanya terdapat satu pusat kegiatan yaitu kawasan industri Balaraja yang berada di radius $4.1 \mathrm{Km}$. Maka dari itu dapat disimpulkan lokasi objek studi berada pada lokasi yang kurang strategis, hal itu karenakan proximity yang tersebar tidak begitu dekat dengan objek studi. Namun berdasarkan Peta RTRW Kabupaten Tangerang 2011-2031, dalam radius $5 \mathrm{Km}$ terdapat rencana jalan tol Balaraja - Serpong dan jalan tol Balaraja - Soekarno Hatta. Selain itu disekitar tapak juga terdapat rencana MRT Balaraja - Kelapa Dua (Bagian dari MRT Balaraja - Cikarang) sehingga dapat menambah transportasi umum menuju tapak.

Mengenai tren perkembangan properti disekitar tapak, perkembangan properti tahap awal cenderung berada di Jalan Kresek dan pada tahun 2010 mulai mengarah ke Jalan Raya Saga Bunar, hal itu juga dikarenakan Kelurahan Saga masih banyak terdapat lahan kosong. Kesimpulannya jika dilihat dari tren perkembangan properti lokasi tapak merupakan kawasan yang baru saja berkembang khususnya untuk jenis properti landed house, sedangkan jika dilihat dari arah pengembangan kota arah perkembangan properti mendekati tapak.

Tapak memiliki view menghadap selatan yang secara langsung menghadap Jalan X. Dimensi tapak yang menghadap Jalan X adalah 215 meter. Luas tapak adalah sebesar $13.5 \mathrm{Ha}$. Bentuk tapak cukup bagus karena bentuk tapak sangat beraturan, hal itu akan mempengaruhi luas efektif lahan yang dapat dibangun akan maksimal. Di sebelah barat tapak berbatasan langsung dengan perumahan bersubsidi yaitu Perumahan Salaka Nagara, di sebelah utara tapak berbatasan langsung dengan lahan yang sedang dalam proses pembangunan perumahan bersubsidi yaitu Grand Harmoni 2 Balaraja. Pada sisi timur, masih belum terdapat aktivitas karena masih berupa lahan kosong. Pada sisi selatan tapak berbatasan langsung sengan Jalan $\mathrm{X}$ dan diseberang Jalan $\mathrm{X}$ juga belum terdapat aktivitas karena masih berupa lahan kosong.

Lokasi objek studi menurut Rencana Tata Ruang Wilayah Kabupaten Tangerang diperuntukkan sebagai Permukiman Kepadatan Sedang, maka dari itu rencana peruntukkan dari pengembang sudah sesuai dengan RTRW Kabupaten Tangerang. Berdasarkan Peta Hak Kepemilikan Tanah, lokasi objek studi $60 \%$ adalah Hak Milik, 35\% adalah belum terdaftar, dan 5\% adalah Hak Guna Bangunan (HGB). Dalam keadaan eksisting status objek studi adalah Hak Guna Bangunan (HGB) (sesuai dengan hasil wawancara dengan pengembang). Mengenai nilai lahan, nilai NJOP lahan masih terbilang murah yaitu $\mathrm{Rp}$ 213.000,- / m2, maka dari itu dengan harga yang terbilang murah, lahan ini sangat cocok untuk dikembangkan menjadi perumahan bersubsidi. 


\section{Analisis Kebutuhan Ruang}

Analisis ini bertujuan untuk mengetahui total ruang yang dapat dibangun diatas tapak dengan menggunakan indikator intensitas bangunan RTRW Kabupaten Tangerang 2031.

Tabel 3. KDB di Luar Kawasan (Perda Kabupaten Tangerang Nomor 9 Tahun 2006)

\begin{tabular}{ccc}
\hline Fungsi & $\begin{array}{c}\text { KDB Maks } \\
\text { Perkotaan (\%) }\end{array}$ & $\begin{array}{c}\text { KDB Maks } \\
\text { Pedesaan (\%) }\end{array}$ \\
\hline $\begin{array}{c}\text { Area Komersial } \\
\text { (Toko, Ruko, Rukan, Bengkel, Dst) }\end{array}$ & 70 & 60 \\
\hline Sarana Kesehatan & 50 & 40 \\
\hline $\begin{array}{c}\text { Apartemen, Hotel, dan Gedung } \\
\text { Perkantoran }\end{array}$ & ${ }^{*}$ ) & - \\
\hline Rumah Tinggal & 60 & 60 \\
\hline
\end{tabular}

Sumber: Hasil Olahan Penulis, 2020

Berdasarkan data tersebut maka didapatkan luas lahan efektif yang dapat dibangun properti dan luas lahan non-efektif yang akan dipergunakan sebagai Fasos- Fasum, Jalan, dan RTH untuk kawasan properti itu sendiri.

Tabel 4. Kapasitas Ruang (RTRW Kabupaten Tangerang)

\begin{tabular}{ll}
\hline Luas Total & $13.5 \mathrm{Ha}$ \\
\hline Luas Lahan Efektif & $81000 \mathrm{~m}^{2}$ \\
\hline Luas Lahan Non- Efektif & $54000 \mathrm{~m}^{2}$ \\
\hline Total Ruang & KDB 60\%, KDH Max 35\% \\
\hline RTH & $13.500 \mathrm{~m}^{2}$ \\
\hline
\end{tabular}

Sumber: Hasil Olahan Penulis, 2020

Maka dapat disimpulkan luas lahan objek studi sebesar 13.5 Ha, memiliki luas lahan efektif 8.1 $\mathrm{Ha}$, sedangkan luas lahan non-efektif adalah sebesar 5.4 Ha yang berfungsi sebagai fasos-fasum, jalan, dan RTH. Setelah mendapatkan luas efektif dan non-efektif penulis mengerjakan proyeksi penduduk dan penentuan jumlah unit yang akan dibangun. Proyeksi penduduk pada tahun 2024 di kelurahan Saga adalah 46703 jiwa dengan kepadatan 127 jiwa / Ha. Untuk hasil perhitungan jumlah unit, penulis menggunakan kepadatan penduduk $350 \mathrm{jiwa} / \mathrm{Ha}$ dengan jumlah unit rumah yang akan dibangun 1.182 unit rumah.

\section{Analisis Pasar}

Dalam radius $2.5 \mathrm{Km}$ dari tapak, terdapat 7 perumahan yang memiliki kesamaan karakteristik dan baru dikembangkan. Diantaranya yaitu Perumahan Salaka Nagara, Perumahan Grand Harmoni 2 , dan sebagainya. Segmentasi Landed House, Secara geografis, produk landed house yang akan dikembangkan memiliki segmentasi pasar di wilayah Kabupaten Tangerang terutama di sekitar Saga, yaitu di Kecamatan Balaraja. Secara demografis, segmentasi pasarnya adalah penduduk yang memiliki kelas ekonomi bawah dan menengah. Jenis pekerjaan yang ada yaitu di sektor industri serta perdagangan dan jasa.

Targeting Landed House Landed house yang akan dikembangkan yaitu perumahan bersubsidi. Perumahan bersubsidi terbilang cocok pada objek studi karena objek studi sendiri berada di Saga, Balaraja dimana Balaraja merupakan salah satu pusat kawasan industri yang ada di Kabupaten Tangerang. Oleh karena itu target pasarnya adalah untuk konsumen menengah dan menengah kebawah khususnya ditunjukkan untuk buruh pabrik. 
Positioning Landed House, Sebelum bisa menentukan market positioning, terlebih dahulu dilakukan skoring terhadap objek studi yang dibandingkan dengan kompetitor sekitar. Berdasarkan skoring dan pembobotan, dapat diketahui bahwa nilai jual lahan per $\mathrm{m}^{2}$ yaitu sebesar Rp 1.456.971,- nilai lahan tersebut digunakan untuk menjual kelebihan lahan yang akan digunakan untuk Hook.

\section{Konsep Pengembangan}

Berdasarkan rencana, pembagian luas lahan untuk perumahan bersubsidi adalah sebesar $81.000 \mathrm{~m}^{2}$. Berikut ini merupakan scenario pengembangan dari perumahan bersubsidi tersebut.

Tabel 5. Perhitungan Jumlah Unit

\begin{tabular}{ccccccc}
\hline Peruntukan & Kelas & $\begin{array}{c}\text { Ukuran } \\
\text { Kavling }\end{array}$ & Luas Kavling & Jumlah & $\begin{array}{c}\text { Luas Total } \\
\text { Lahan }\end{array}$ & Persentase \\
\hline Lahan Efektif 60\% & & & & 1182 & 7000 & \\
\hline Hunian 60\% & $\begin{array}{c}\text { Menengah } \\
\text { Bawah }\end{array}$ & $6 \times 10$ & 60 & 10080 & \\
\hline $\begin{array}{c}\text { Lahan Non Efektif } \\
\text { 40\% }\end{array}$ & & Sisa Lahan & 54000 & \\
\hline $\begin{array}{c}\text { Jalan + Saluran } \\
\text { 50\% }\end{array}$ & & & & 24300 \\
\hline $\begin{array}{c}\text { Fasos - Fasum } \\
\text { 25\% }\end{array}$ & & & 13500 \\
\hline RTH 25\%
\end{tabular}

Sumber: Hasil Olahan Penulis, 2020

Produk hunian tapak bersubsidi yang akan dikembangkan hanya terdiri dari 1 tipe yaitu tipe 60 (6x10), hal itu dikarenakan pihak pengembang (developer) bekerja sama dengan Bank BTN dimana Bank BTN hanya mengembangkan 1 tipe perumahan bersubsidi yaitu tipe 60 , hingga saat ini pihak Bank BTN belum mengembangkan rumah subsidi dengan tipe lainnya walaupun peraturan pemerintah sudah menambah peraturan luas maksimal untuk perumahan bersubsidi yaitu hingga $72 \mathrm{~m} 2$.

Hasil perhitungan cash out landed house dapat dilihat pada lampiran 6. Biaya yang dikeluarkan untuk mengembangkan perumahan bersubsidi selama 3 tahun sampai dengan tahun 2023 adalah $\mathrm{Rp} 154,557,726,395.33$,-. Sedangkan hasil perhitungan cash in landed house dapat dilihat pada lampiran 6. Hasil dari perhitungan cash in pengembangan yaitu sebesar Rp $224,460,267,680.00,-$. Total perhitungan tersebut terdiri dari hasil penjualan rumah subsidi sebanyak 1.182 unit rumah.

Hasil perhitungan cashflow landed house dapat dilihat pada lampiran 7. Berdasarkan hasil perhitungan cash flow dari pengembangan landed house, diketahui bahwa proyek tersebut layak untuk dikembangkan. Pengembangan dapat dikatakan layak setelah melihat beberapa indikator, yaitu:

Tabel 6. Cash Flow Pengembangan

\begin{tabular}{lr}
\hline Suku Bunga & $10.5 \%$ \\
\hline Net Present Value (NPV) & Rp 26,400,222,683.35 \\
\hline Internal Rate of Return (IRR) & $28 \%$ \\
\hline Payback Period (PP) & 1.92 (Tahun Ke-2 / 2022) \\
\hline Profitability Index (PI) & 1.15 \\
Sumber: Hasil Olahan Penulis, 2020 &
\end{tabular}


Berikut ini merupakan gambar siteplan yang penulis buat untuk lahan pengembangan milik PT. Prima Graha Nusa Sempana seluas 13.5 Ha yang akan dikembangkan menjadi perumahan subsidi.

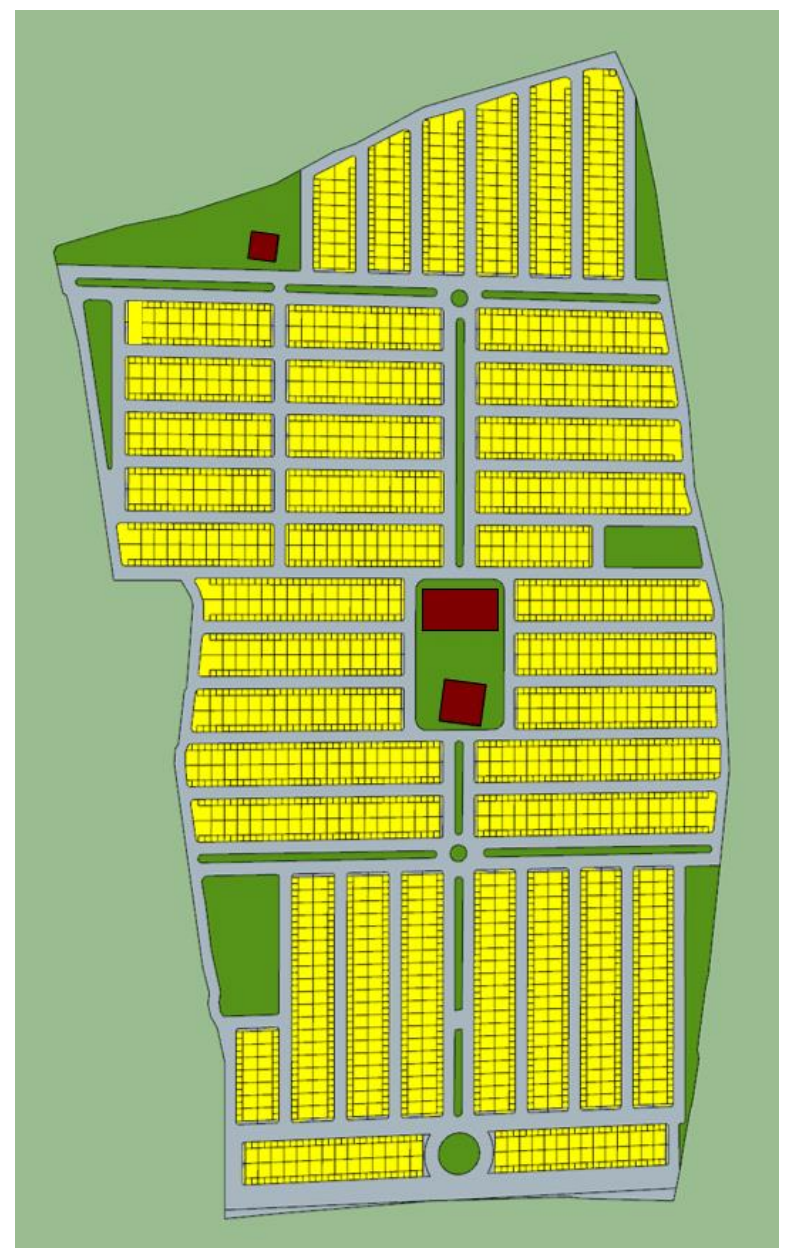

Gambar 3. Siteplan Landed House

Sumber: Hasil Olahan Penulis, 2020

Berikut ini merupakan ilustrasi tampak rumah subsidi dan denahnya yang penulis usulkan untuk pengembangan Perumahan Saga.

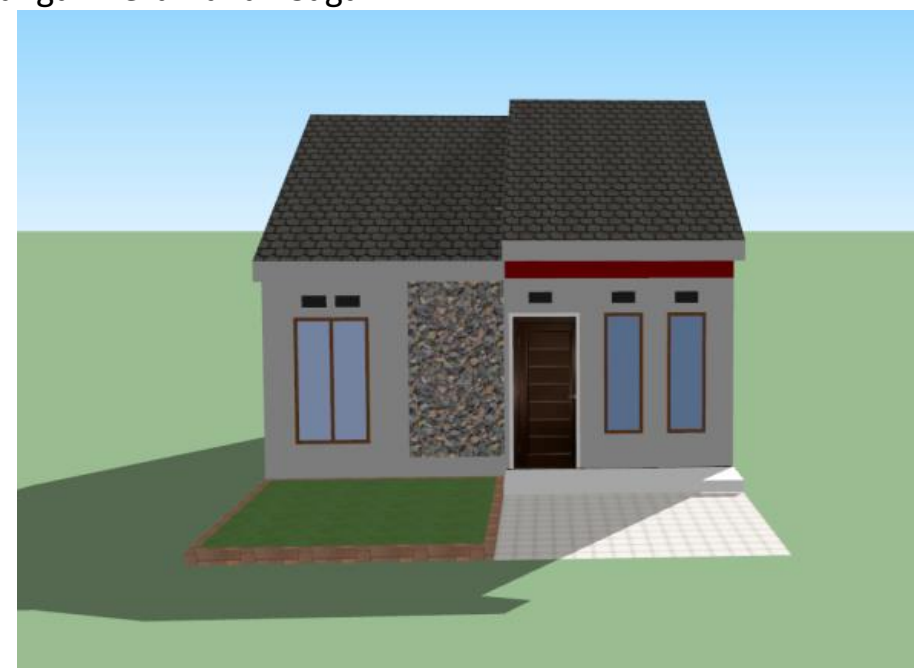

Gambar 4. Siteplan Landed House

Sumber: Hasil Olahan Penulis, 2020 


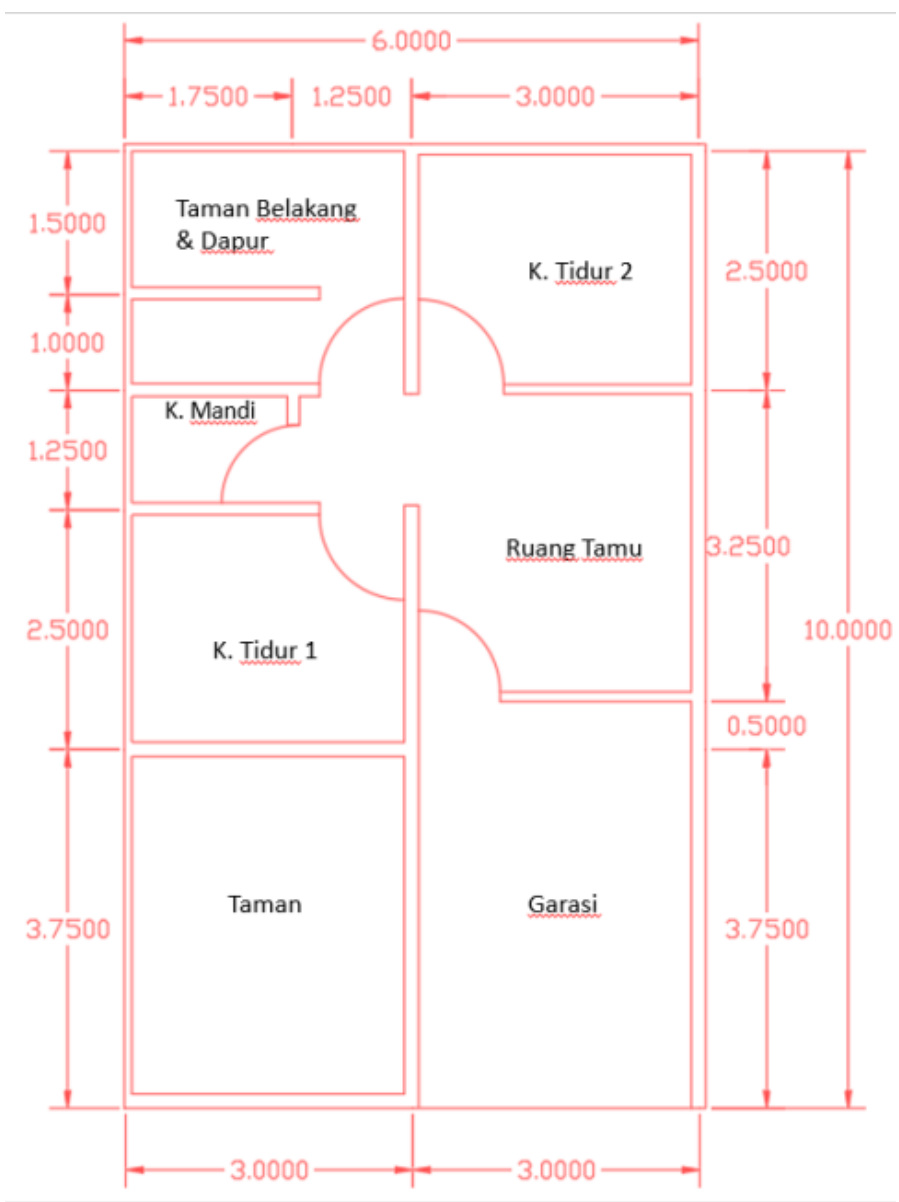

Gambar 5. Siteplan Landed House

Sumber: Hasil Olahan Penulis, 2020

\section{KESIMPULAN DAN SARAN}

\section{Kesimpulan}

Berdasarkan analisis lokasi, untuk mencapai tapak hanya memiliki satu akses yaitu melalui Jl. Raya Kresek lalu menuju Jl. Raya Saga Bunar, dan masih harus melalui Jl. Y untuk menuju tapak. Tetapi walaupun akses menuju tapak masih terbilang kurang, lokasi tapak berada di Balaraja dimana balaraja merupakan salah satu pusat kegiatan industri di Kabupaten Tangerang. Letak kawasan industri Balaraja berada di radius $4.1 \mathrm{Km}$ dari lokasi tapak. Dalam radius $3.8 \mathrm{Km}$ juga terdapat pintu tol Balaraja Barat. Selain itu berdasarkan Peta Rencana Pola Ruang Kabupaten Tangerang dalam RTRW Kabupaten Tangerang 2011-2031, dalam radius 2Km terdapat rencana MRT Balaraja - Kelapa Dua (Bagian dari MRT Balaraja - Cikarang) yang artinya dapat menambah transportasi umum menuju tapak. Jika dilihat dari tren perkembangan properti lokasi tapak merupakan kawasan yang baru saja berkembang khususnya untuk jenis properti landed house, sedangkan jika dilihat dari arah pengembangan kota arah perkembangan properti mendekati tapak.

Berdasarkan analisis tapak, bentuk tapak cukup bagus karena bentuk tapak sangat beraturan, hal itu akan mempengaruhi luas efektif lahan yang dapat dibangun akan maksimal. Mengenai peruntukan, rencana pengembangan lahan sudah sesuai dengan peruntukan RTRW Kabupaten Tangerang yaitu sebagai kawasan permukiman dengan kepadatan sedang. Mengenai nilai lahan, nilai NJOP lahan masih terbilang murah yaitu $\mathrm{Rp} 213.000,-/ \mathrm{m}^{2}$, maka dari itu dengan harga yang terbilang murah, lahan ini sangat cocok untuk dikembangkan menjadi perumahan bersubsidi. 
Berdasarkan analisis kebutuhan ruang, menurut Perda Kabupaten Tangerang Nomor 9 Tahun 2006 tentang rencana tapak, maka didapatkan luas lahan objek studi sebesar $13.5 \mathrm{Ha}$, memiliki luas lahan efektif $8.1 \mathrm{Ha}$, sedangkan luas lahan non-efektif adalah sebesar $5.4 \mathrm{Ha}$ yang berfungsi sebagai fasos-fasum, jalan, dan RTH. Setelah mendapatkan luas efektif dan non-efektif penulis mengerjakan proyeksi penduduk dan penentuan jumlah unit yang akan dibangun. Proyeksi penduduk pada tahun 2024 di kelurahan Saga adalah 46703 jiwa dengan kepadatan 127 jiwa / Ha. Untuk hasil perhitungan jumlah unit, penulis menggunakan kepadatan penduduk 350 jiwa/Ha dengan jumlah unit rumah yang akan dibangun 1.182 unit rumah.

Berdasarkan analisis pasar, perumahan bersubsidi terbilang cocok pada objek studi karena objek studi sendiri berada di Saga, Balaraja dimana Balaraja merupakan salah satu pusat kawasan industri yang ada di Kabupaten Tangerang. Target pasarnya adalah untuk konsumen menengah dan menengah kebawah khususnya ditunjukkan untuk buruh pabrik. Dilihat dalam radius $2.5 \mathrm{Km}$ dari tapak, terdapat 7 perumahan yang memiliki kesamaan karakteristik dan baru dikembangkan. Sesuai dengan perhitungan beberapa kompetitor disekitar tapak maka didapatkan harga tanah $\mathrm{per} / \mathrm{m}^{2}$ yaitu $\mathrm{Rp}$ 145.697,-. Maka dari itu dapat disimpulkan bahwa lahan cocok dikembangkan sebagai perumahan subsidi.

Berdasarkan konsep pengembangan, dalam konsep pengembangan, dilakukan perhitungan cashflow yang tujuannya untuk melihat layak atau tidaknya peroyek perumahan subsidi pada tapak tersebut. Dalam perhitungan cashflow dilakukan perhitungan alternatif bahan bangunan, yaitu alternatif $1 \& 2$, berikut ini merupakan perbandingan dari alternatif bahan bangunan $1 \&$ 2.

Tabel 7. Perbandingan Alternatif Bahan Bangunan

\begin{tabular}{|c|c|}
\hline Bahan Bangunan 1 & Bahan Bangunan 2 \\
\hline $\begin{array}{l}\text { - Menggunakan Bata Ringan } \\
\text { Vascon }\end{array}$ & - Menggunakan Bata Ringan Habel \\
\hline $\begin{array}{l}\text { - Menggunakan Atap Spandek } \\
\text { Zuncalume }\end{array}$ & $\begin{array}{l}\text { - Menggunakan Genteng Metal } \\
\text { Sakura Roof }\end{array}$ \\
\hline - Tidak terdapat aksen minimalis & $\begin{array}{l}\text { - Menggunakan Batu Alam Teras } \\
\text { Centro agar rumah terlihat lebih } \\
\text { minnimalis }\end{array}$ \\
\hline & $\begin{array}{l}\text { - Menggunakan daun jendela } \\
\text { Bouvenlight }\end{array}$ \\
\hline - Biaya total : Rp 65.730.400,- & - Biaya total : Rp 70.144.500,- \\
\hline
\end{tabular}

Sumber: Hasil Olahan Penulis, 2020

Lalu setelah dilakukan perhitungan alternatif bahan bangunan penulis memilih alternatif bahan bangunan 2, karena memiliki beberapa keunggulan bahan bangunan seperti batu bata ringan yang digunakan, pemilihan atap/genteng, dan yang paling utama ialah penambahan aksen minimalis terhadap rumah. Setelah dilakukan perhitungan, hasilnya menunjukkan bahwa pengembangan perumahan subsidi pada tapak seluas 13.5 Ha milik PT Prima Graha Nusa Sempana adalah layak. Setelah itu dilakukan pembuatan siteplan, ilustrasi denah, dan ilustrasi tampak bangunan.

\section{Saran}

Saran yang penulis berikan untuk lahan pengembangan milik PT Prima Graha Nusa Sempana ialah berupa jumlah unit yang dibangun yaitu sebanyak 1.182 unit rumah dengan ukuran 36/60 sebanyak 1018 dengan luas total $61080 \mathrm{~m} 2$ dan dengan ukuran 36/80 untuk rumah yang berada 
di hook sebanyak 164 dengan luas total $13120 \mathrm{~m} 2$. Selain itu penulis menyarankan siteplan, ilustrasi denah, dan ilustrasi tampak bangunan untuk pengembangan perumahan subsidi tersebut.

\section{REFERENSI}

Firmansyah, A. Y. (2011). Rancang bangun aplikasi anggaran biaya dalam pembangunan rumah. surabaya.

Husnan, S. S. (2000). Studi kelayakan proyek. Yogyakarta: UPP AMP YKPN.

Kotler, P. (2005). Manajemen pemasaran. Jilid 1 dan 2. Jakarta: PT Indeks Kelompok Gramedia.

Kyle, R. C. (1991). Property management. Real Estate Education Company.

Mangeswuri, D. (2016). Kebijakan pembiayaan perumahan melalui fasilitas likuiditas pembiayaan perumahan (FLPP). Jakarta Pusat: Jurnal Ekonomi Kebijakan Publik. Vol.7.

Santoso, B. (2009). Property crash. Jakarta: PT Elex Media Komputindo.

Sunyoto, D. (2014). Studi kelayakan bisnis. Yogyakarta: CAPS (Center of Academic Publishing Service).

Umar, H. (2005). Studi kelayakan bisnis, Edisi 3. Jakarta: Gramedia Pustaka Utama. 
